\title{
Uncovering Failures of Game Design for Educational Content (and how to fix them)
}

\author{
Kay Berkling, Heiko Faller and Micha Piertzik ${ }^{1}$, Wolmet Barendregt ${ }^{2}$, and \\ Laura Benton ${ }^{3}$ \\ ${ }^{1}$ Cooperative State University of Baden Württemberg, Computer Science, \\ Erzberger Str. 121, Karlsruhe, Germany \\ berkling@dhbw-karlsruhe.de, heiko_faller@t-online.de, \\ official@piertzik.vip, \\ 2 University of Gothenburg, Divison of Learning Communication and ICT, \\ Forskningsgången 6, 41296 Gothenburg \\ wolmet. barendregt@ait.gu.se \\ 3 University College London, UCL Institute of Education, \\ 20 Bedford Way, London WC1H 0AL, UK \\ 1.benton@ucl.ac.uk
}

\begin{abstract}
More than 800 users from a cross-section of ages and gender were asked about the games they play and what motivates them to play these. The answers were cross-matched with game features. Based on this match and subjective answers of those surveyed, a pattern emerges for the essential ingredients of addictive games across these demographics, as well as an anti-pattern. With the derived pattern and anti-pattern several games and real-world scenarios can be designed and existing ones analyzed. Examples show how the pattern or anti-pattern can be applied and elucidate which key ingredients tend to be missing.
\end{abstract}

Keywords: Games, Content, Design, Addiction, Education, Gamification, Analysis

\section{Introduction}

Playing games, pursuing a sport or enjoying a hobby can be both fun and addictive. In contrast to those contexts (that also often include learning) however, learning in the official context of school is often stressful or perceived as a duty. It is rare to find students who cannot wait to get up in the morning to continue their learning from the previous night, although this is more frequent in first grade than the later years. To improve the learning experience, researchers and educators have introduced games into the classroom in different ways: By using existing games in class or adding gamification mechanics to educational content. Not all educational or serious games show the desired effect of playfully or addictively engaging students to master perfection of a certain skill. In this paper, we build on previous work [3] that has derived pattern elements that appear 
in addictive mobile games in order to see how this knowledge about design can be incorporated into games with academic content; anti-pattern elements were established as a by-product of this process. For the purpose of self-containment, these findings are summarized here and then subsequently applied to several games and school environments for design and analysis. Comparing these along the pattern and anti-pattern elements, it can be shown that certain important aspects can easily be missed and offer a hint at how to improve the player experience.

In the following section, we briefly introduce the concepts and current understanding of games, gamification and motivation in the educational and demographic context, with a focus on literature overview papers.

Gamification: Gamification pertains to the analysis of mechanics that make games fun and then applying these to situations outside of gaming in order to recreate the feeling of fun or addiction to new applications such as learning or marketing or the solving of mundane tasks (rephrased from Oxford Dictionary).

According to [26], there have been a number of papers on various topics relating to gamification in education. Very few, however, deal with actual game design for experience, solution proposal, and validation with respect to mastering skills.

Dicheva [11] lists the papers that have studied various features in gamification usage for education. The most frequently studied mechanics in order of popularity are: "Status", "Social Engagement", "Freedom of Choice", "Freedom to Fail", "Rapid Feedback" and "Goals and Challenges". Researchers have studied gamification of educational material and shown that there is a strong interest in using game mechanics for education.

We believe that there remains a significant gap in actually designing and validating the use of games with educational content, going beyond gamification ${ }^{4}$.

Games: Game-based learning (GBL) builds games or leverages existing games, such as Civilization, and re-uses them for an educational purpose, like economics or history $[27,34]$. Games are just starting to make a very slow move into schools $[12,24]$. The idea of using games in education is sometimes treated differently in the literature and called Educational Games or Serious Games (for example, [33]). These are designed specifically with educational content in mind. For the purpose of this paper, we prefer not to distinguish between games and serious games (this is not unusual and seems to agree with the findings in the literature overview on the subject [9]). According to Merriam Webster, a game is defined as: a) A form of competitive activity or sport played according to rules; b) An activity that one engages in for amusement; c) (adj) eager or willing to do something new or challenging. In this sense, there is no need to give a special name to a game that has educational content. The focus is instead on how the content is designed as a game (for example pure game design [13], and its effect on children's learning outcome [29] and [5]).

\footnotetext{
${ }^{4}$ Academic or educational content for our purposes refers to content defined in the context of school.
} 
Extrinsic vs Intrinsic: The difference between extrinsic and intrinsic motivation has been described extensively [23], as well as the negative effects of extrinsic motivators on intrinsic motivation and performance. Recently, Hanus [14] has shown the effects of gamification in the classroom in a longitudinal study:

- "Over time, gamified students were less motivated, empowered, and satisfied.

- Gamified courses negatively affected final exam grades through extrinsic motivation.

- Gamified systems strongly featuring rewards may have negative effects."

With "Educational" Games and gamification we often obtain, as a result, exactly this sort of extrinsic motivation by providing unrelated rewards. In contrast, popular games themselves seem to tend more towards the intrinsic motivation and working with the provided content to learn something. In this paper we would like to contribute towards moving education in the direction of understanding how to design and use games with educational content.

Demographic Dependence: Using game mechanics to design an addictive educational experience has been studied in detail. It is well known that personas, typical user profiles of a known demographic, are necessary for good design. Koivisto and Hamari [16] have shown that age and gender play a major role when designing gamification mechanics for their respective demographics. The work presented here incorporates demographics but looks at common themes across demographics for general audiences in education.

Relationship between Education and Games: Vallerand [32] explains in a very valuable summary the key to seeing education as a game: It is important to identify the intrinsic rewards relative to the culture and build game-like interactions on top of these by focusing on mechanics like "Freedom to Fail, Rapid Feedback, Progression and Storytelling" - note that these overlap with those studied in the gamification literature (Section 1). Stott [28] then makes the connection with existing terminology in education. "The Freedom to Fail" is analogous to formative assessment using "Rapid Feedback", "Progression" relates to scaffolded learning and "Storytelling" is equally recognized as a powerful tool in the classroom.

What we can learn about the current culture of games and what engages our time in gaming? The subject of this paper is a more detailed recipe-like mapping between these two areas.

Current Cultural Framework: The dynamics of change regarding which features in games are perceived as fun or addictive are not well studied. A similar approach to using design guidelines to create fun was developed by Malone and colleagues in the 1980s [18]. Based on his experience and analysis of games, he developed a taxonomy, a recipe to be used for game design. We will briefly compare our recipe to this taxonomy in Section 4.1. Some of these features in games may have universal appeal as they have remained constant over the years, while others might be dependent on current interests. This paper contributes to 
the general knowledge in the area by providing an updated analysis on what motivates gamers today.

The rest of the paper is organized as follows. Section 2 explains the framework that was developed through a detailed study of 27 popular mobile games. Based on this framework, a survey of over 800 participants was conducted and the results are described in more detail in Section 3. More details on this survey are given in [3] Section 4.1, which describes the resulting recipe or pattern that should guide successful game design. Section 4.2 specifies the corresponding antipattern. In the next two sections we will first show how the pattern or recipe can be used to design games (Section 5) and then demonstrate how the pattern can be used to analyze game environments in (Section 6). All examples contain educational content. Finally, Section 8 summarizes and proposes future work.

\section{Analysis of Games}

A list of popular mobile games from the Google Play Store charts as well as from the subjective experience of Bachelor students (two of the co-authors of this paper are Bachelor students with first-hand access to this information) is compiled. This list forms the basis of the questionnaire to analyze the features of these games in relation to the demographics of the players.

The list of games that are chosen for the study is as follows:

FIFA, Pineapple Pen, Block! Hexa Puzzle, Piano Tiles 2, Rolling Sky, Subway Surfers, Clash of Clans, Flippy Bottle Extreme, Color Switch, Roll the Ball, Temple Run, Pou, Hill Climbing Racing, Candy Crush, Angry Birds, Fruit Ninja, Geometry Dash, Cut the rope, 2048, Doodle Jump, Plants vs. Zombies, Jetpack Joyride, Stack, Dumb ways to die, Flappy Bird, Minesweeper, and Tetris.

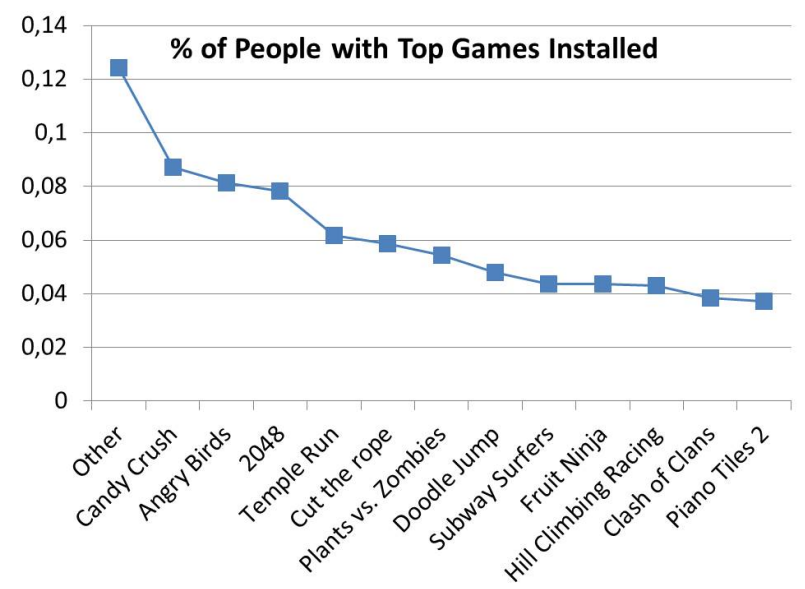

Fig. 1. Popularity of Games. (See also [3]) 
Figure 1 depicts the distribution of users that selected this game as installed on their mobile device.

Four main categories of distinguishing features evolved out of an iterative analysis of the games list: Game-mode, Motivation, Emotion, Simplicity (as well as other features not categorized). These are each explained below (examples and feature assignment are given in [3]).

Game Mode: Games can be distinguished by game mode. These usually fall into one of these categories: Single level (Pineapple Pen), multiple level (Angry Birds), or storyline (Clash of Clans).

Motivation: Motivation for games are simple game mechanics that create extrinsic motivation such as listed below. We distinguish between rewards and currency that serves as a mechanism to acquire new tools to help the player progress. Goals define specific "tasks" that have to be accomplished irrespective of levels. Come-back motivations are types of appointments. High-score is a form of competition with self or others and a progress bar shows the path towards a goal or level.

Emotion: A major factor in games are emotions that can be supported with emotional faces, sound or graphics. Furthermore, fun, humor and spectacular death can support the creation of strong emotions for the player.

Simplicity: Simplification is important for on-boarding and ease of movement across levels of difficulty. It should be easy to start and proceed. The menu has to be quick, direct and easy to understand:

Other: Other factors that do not fit into the above categories have been determined as important aspects of a number of games that are currently popular: Their relation to reality, patterns that are learned to improve performance, social behavior (like feeding the animals in a friends' zoo) or competitions with self or others.

\section{Survey: Design and Results}

In order to gain a deeper understanding of how we can use games in education and generalize their design across populations, a survey reflecting current interests was conducted. The survey builds on the features that we have defined in the previous section.

\subsection{Survey Construction}

The survey includes the following sections (more detail is given in [3]):

- Demographic data

- Gaming Habits 
- Games Installed and general Motivators

- Favorite Game and specific Motivators

- Emotions and their initiators

The evaluation of the survey should increase insight into the motivators based on three methods of eliciting information:

1. Installed games indicate interests indirectly though the framework,

2. Explicit motivation to play a favorite game, and

3. Indirect indicators of motivators that create a favorite emotion as a reason for playing.

These three insights allow us to understand how games can be designed with academic content.

\subsection{Demographics of Participants}

The survey, using Google forms, was announced via a Facebook games website and through university networks as well as employers. The result is a representative mix of people from industry and university, as well as a cross-section of different age groups and genders. Figure 2 depicts an overview of the population that answered the survey. In total 893 people responded to the survey within two weeks of posting it. Table 1 presents a breakdown of the respondents within each of the four categories of interest to us.

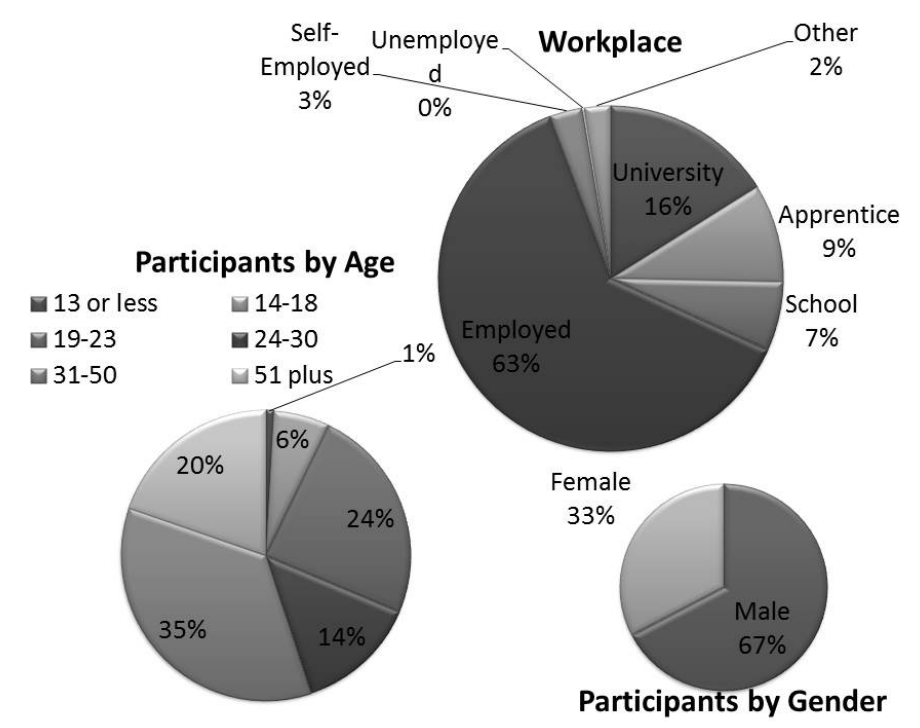

Fig. 2. Survey Demographics. (See also [3]) 
Table 1. Participant numbers by Male/Female and Age bracket ( $<23$ vs. $>31)$. (See also [3])

\begin{tabular}{|l|c|c|}
\hline Subgroups & $<23$ & $>31$ \\
\hline Male & 173 & 347 \\
\hline Female & 107 & 145 \\
\hline
\end{tabular}

\subsection{Results of Motivators in Favorite Game}

Specific questions regarding motivators were asked within the context of the respondents favorite game. In particular distinguishing features of games were queried: Goals, Rewards, Competition, Friends, and Emotions. These points are compared across the four demographic groups defined above. Within the Likert scale from 1-6 (1=not at all and $6=$ very much), groups 1-3 and groups 5-6 are joined. The values in Table 2 represent the chance ${ }^{5}$ that the resulting two queried subgroups respond differently to each motivator.

It shows that competition is of differing importance for males and females, regardless of age. Goals and Emotions have differing importance for younger vs. older males, Emotions differ also between younger males and females. Goals and Rewards are assimilated with age for both genders (see also [3]).

Table 2. Significance in differences between subgroups by $\%$ of chance that the two querried groups will differ in their reponse. (YM, YF, OM, OF = Younger/Older Male/Female) (See also [3])

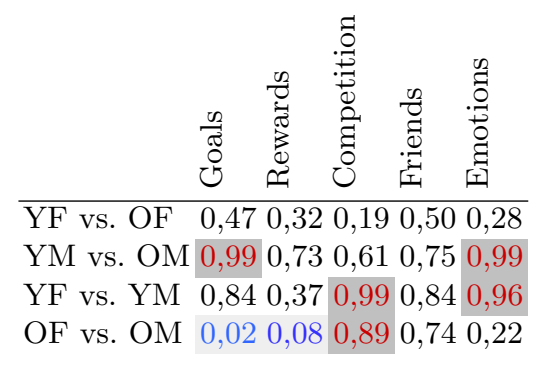

In order to understand more closely which emotions are important when playing and how these are created, one question in the survey asks about emotions regarding a specific favorite game. Namely, which emotion is produced by the game and how this emotion is established. An interesting commonality is found here. Both genders and age groups play for fun and enjoyment, and each group has mostly minor differences in opinion on how this fun factor is established. Namely excellent graphics, the ability to improve oneself and the increasing dif-

\footnotetext{
${ }^{5}$ This calculation is based on N-1 Chi-Square test as recommended by [10], using the 2-tailed p-value.
} 
ficulty. The distribution is shown in Figure 3 . These results corroborates findings from game design and Psychology (for example, $[17,8]$ ).

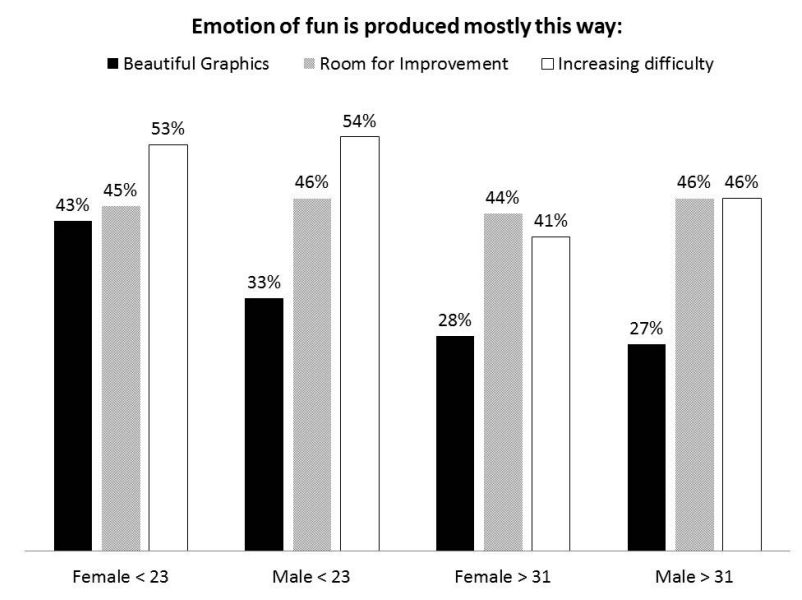

Fig. 3. Commonalities on most important emotion and how this emotion is created. (See also [3])

\subsection{Results of Motivators in General}

Based on the installed games on people's mobile devices, we can establish a profile to describe which game features are favored as a function of gender or age. Equation 1 defines the cross product between the number of people within the subgroup who have installed a particular game on their mobile device with the feature vector (see [3]). This value represents a preference for a given motivator, or feature, with a particular group of respondents to the survey.

$$
\text { Value }_{(\text {Subgroup } \wedge \text { Feature })} \frac{\sum_{i}^{\text {games }}\left(X_{i} Y_{i}\right)}{\sum_{i}^{\text {games }} X_{i} \sum_{i}^{\text {games }} Y_{i}},
$$

where $X$ is the vector of persons in a particular subgroup who have this game installed given the subgroup and $Y$ is the analysis vector for a particular game feature across all games. This Vector has a 1 if the feature exists and a 0 if the feature does not exist (see also [3]).

The resulting values can then be compared across subgroups ( [3]) and result in the following trends (among others):

- Differences between females and males get more pronounced as they get older.

- Males like faces, humor and a fun death.

- Older people need more goals. 
- Females like a incentive to return.

- Females tend to be more interested in levels than males. This is less pronounced in younger ages.

- Some differences between gender are more pronounced in the older demographic.

- Figure 4 shows items that are most sensitive to gender specific demographics. Among these are also levels, rewards and competition that will be discussed in more detail later.

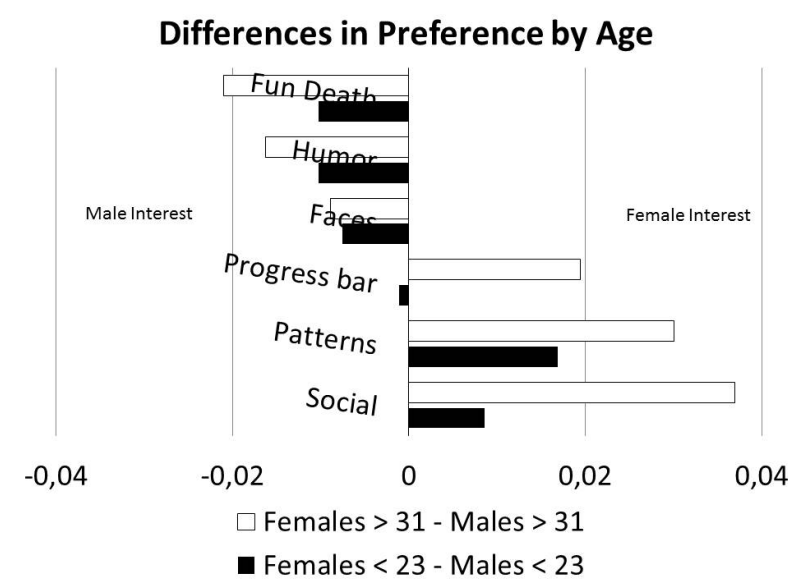

Fig. 4. Selected motivators showing differences in gender for younger and older demographic groups. The younger demographic tends to have less pronounced differences. (See also [3])

Based on the feature preferences across the games we can establish that there are indeed differences when looking across all the various features that games have. While this information shows implicitly which features are preferred through the games that are installed, it is not guaranteed that all installed games become favorites. So, they do not necessarily represent a true picture of favorite games choices. However, they may serve as an indicator given the large set of data obtained from the survey. The next step is to compare features specific to favorite games.

\subsection{Results of Direct Questions about General Motivators}

Looking more specifically and detailed at the motivators of Levels, Rewards and Competition, questions were asked in reference to the respondent's favorite game. While levels seem to be favored in different ways by particular demographic groups, a more detailed examination shows commonalities. Figure 5 depicts the 
relative importance of levels in games for both males and females in general and in their favorite game. All demographics, whether in general or specific to their favorite game, favor levels.

The graph on the left hand side in Figure 6 shows that there are different types of rewards. In general rewards may not be important to players (only $20 \%$ of players care about rewards that are not useful for advancement). However, looking in more detail at different types of rewards, there are differences. If the reward pertains to gaining more power or skills in the game, they are of interest to a larger number of people (about $60 \%$ ) than simple rewards that do not help the player. This finding holds true across all demographics.

The graph on the right hand side in Figure 6 depicts preferences for several different types of competitions that can be used in games. It shows that certain types of competition are more interesting than others. While there are gender differences, there is some agreement across demographics that competition with self is more preferred than global competition.

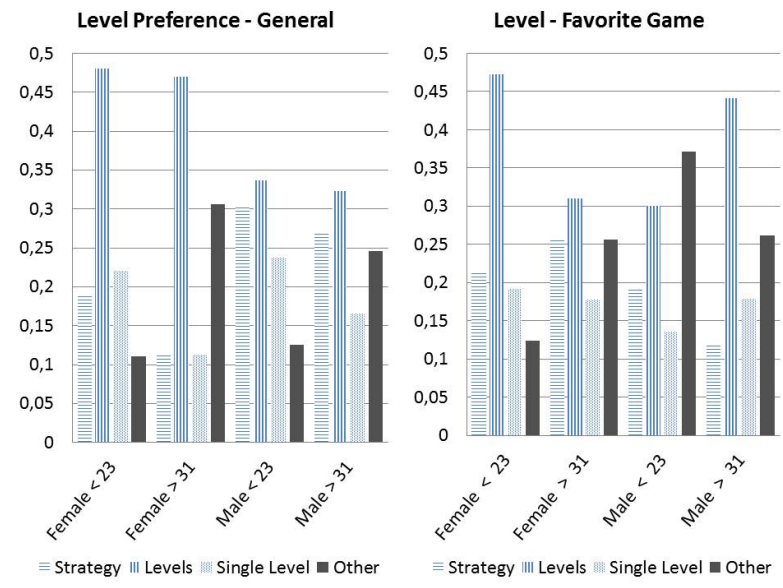

Fig. 5. How important are levels? (See also [3])

\subsection{Summary and Conclusion of Survey Results}

Looking at implicit and explicit preferences in motivators, we have shown differences in demographic subgroups. But more importantly, we have gained insights into commonalities that are necessary to design a game for the general public regarding motivators for academic content learning. The survey shows how levels, competition and rewards have to be carefully used within a good design. With the gained knowledge, we can define anti-patterns, how not to use a game in the classroom or how to not design a game with academic content. Similarly, we can also define good practice on how to present content to users. Using this 

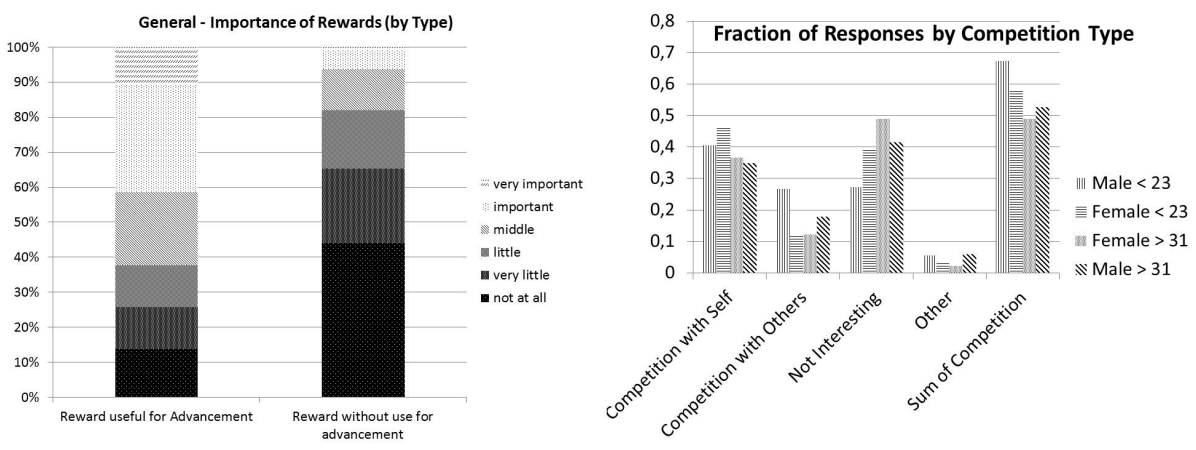

Fig. 6. Which types of competition are preferred? How important are rewards?

framework, we can now look at several games or gamified environments in order to see how they compare to universally addictive games. This in turn will help us to see which areas are typically not part of the game design and how they can be improved.

\section{Framework for Pattern and Anti-Pattern}

This section defines the pattern and anti-pattern based on the study and findings. These will subsequently be used to design and analyze several games with academic learning content as well as two classroom situations. The goal is to see where some of the academic games may lack features that are important in games and contribute to the desire to play.

\subsection{Pattern: Recipe for Good Design}

Based on the findings of the 2016 survey on how games are played explicitly as well as implicitly, one can establish a checklist of important design elements when building a game around academic content for the general public, that is, they hold mostly true across the demographics that were polled. (Future research should focus on how well these generalize to younger children.)

In general, the following points are absolutely essential and can not be bypassed:

- Graphics (Consistent and Simple)

- Rewards (Must relate to capabilities)

- Increasing Difficulty

- Increased Knowledge (replay until expert)

- Easy to start and stop playing

- Competition with Self

- Leave out everything else 
Design steps should include the usage of levels in the following way:

- Many Levels (Consistent and Simple)

- Frequent new elements

- Levels can be infinite (level-based improvements)

- Don’t use single level

Pedagogical design, such as scope and sequence of content seems to be inherent to this recipe. When comparing to Malone's taxonomy of intrinsically motivating game design elements, some of his items (like social interaction) were not found to be generic for all players covered in the survey. Other elements were present, but in a slightly more explicit form. For example, while Malone's taxonomy mentions goals in general, the survey shows that goals in the form of levels and competition with oneself are especially motivating. Furthermore, in his taxonomy emotion plays an important role, while we break apart which components of the game create this emotion for the player. It was found that emotion can be created by self-improvement, graphics and increasing difficulty. While some of these items are also listed in Malone's taxonomy, the connection to the emotion is not explicitly drawn. There is a strong overlap however with Malone's taxonomy regarding the tight interconnection between the game design and the learning content that is apparent in our recipe. Curiosity, control and fantasy are equally important in both design proposals. This comparison can be an indication of the universality of some of these features to the human nature of play.

\subsection{Anti-Pattern}

Game design can be done badly and it is of interest to define an anti-pattern, a pattern for bad design (when designed for a general population). The following checklist is generated from the survey results.

- Single Level (fits fewer demographics)

- Bad Graphics (Crowded, low quality (unless funny), unrelated to content): For example, too many icons, graphic elements and texts.

- No rewards or unrelated rewards (that do not contribute directly to increased skill)

- Little self-awareness of skill increase

- Too complex on-boarding or advancement

- Long units of play necessary

- No view of own high-score to compete with

- No replay of level - ie. no chance to improve

- Too much material at the same time (unleveled)

- Path too restrictive (no choices)

Levels can be designed badly as follows:

- Few levels 
- Too many repetitions, no new elements

- No individual speed

- Competition with others

- No improvement in finished levels possible

\section{Game Design}

We look at two games that have been designed with these patterns in mind. In addition, a course designed in a school setting is described from the game point of view.

\subsection{Software Engineering Classroom}

In previous work, a Software Engineering course was gamified and then modified to improve student motivation in the classroom. The redesign was also based on student feedback and matches the pattern closely $[6,7]$.

Students are asked to submit their homework not on a central platform that is chosen by the professor or the university but on a blog platform of their choice that they have designed and configured themselves. Rewards, ie. points are given for each submitted homework and relate directly to the final grade as well as the project. At the same time, these points show how much of the final project has been finished already. Each new homework builds on the previous knowledge. However, there are no unlocks of levels visible to the student. Students report that they find this course very challenging. The "progress bar" regarding the homework that has already been handed in shows how the students are moving through the material. Looking back on their semester, students agree that the things they were able to do after one year could not have been possible at the beginning. Nor could the last lesson have been taught in the first week. Student feedback regularly shows an improvement in the nine areas of learning. The change in self-evaluation of skills is shown in Figure 7. Playing for short intervals is difficult in the context of a classroom but in a project-based course, there are always small tasks that can be approached in short time intervals. Students are expected or encouraged to hand in their assignments repeatedly until they are perfect. This is in contrast to traditional classrooms where the assignment ends after submission. The reviews are accomplished through peer reviewing [2]. There is little information in the course that does not pertain to the homework of the current level or week. Students can be observed to work on-task throughout class time.

If one can think of homework as a level, then there are 17 levels to be passed over the course of two semesters in order to submit the final project that consists of the combination of the 17 mastered levels. Each week, a new element is added to the previous knowledge and this has to be fulfilled by the end of the week for the assignment. Each homework is resubmitted until perfection. Peer review supports this process. The homework helps to distinguish the different tasks. Taking a brief look at the anti-pattern can help to review whether there are 


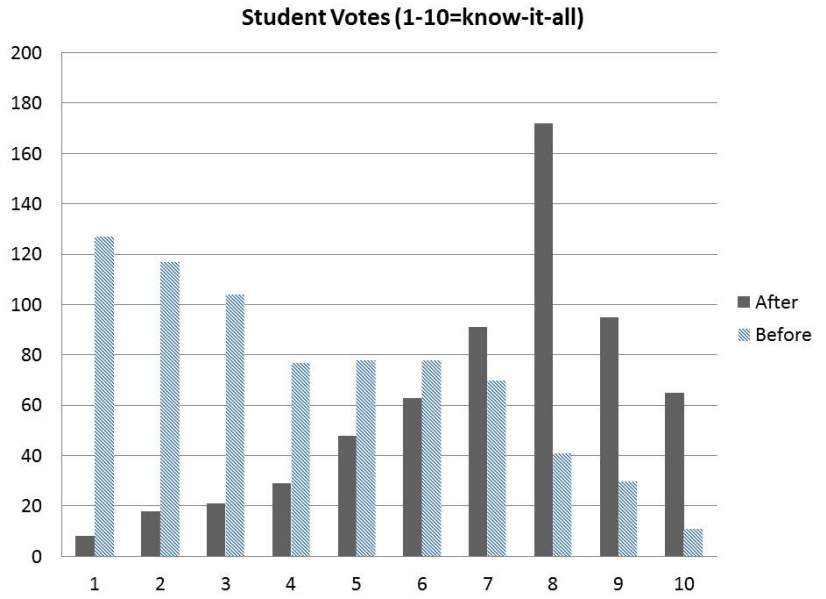

Fig. 7. Software Engineering self evaluation on the nine skills on a scale from 1 (I know nothing) - 10 (I feel that I know this topic well). Answers are summed across all questions for each of three classrooms with an average of 25 students each, before and after the completion of the course.

still remaining design flaws that are obvious. There is no single exam at the end of the course, which would be the equivalent of a single level game. Students are responsible for setting up their own blog and thereby also their own graphic interface configuration. In the past, bad learning platforms were one of the major complaints that students have had. This is no longer true for the current course design. Self-awareness of skill increase could probably be improved. However, the progress bar supports visualization of progress, as does the growth of the blog length. On-boarding is easy, fast and satisfactory because it includes building their own platform and that is fun and easy. The first homework is easy and focuses on process over content as well as defining their own project. A unit of play is only one week (short in a school setting). You do not compete with others, only yourself. There is no leaderboard. Yet, there is some kind of peer pressure by seeing what others are accomplishing. At the same time, students are able to see their own score and improve it. They can replay any assignment (level) as often as they wish to gain the perfect grade, ie. the perfect project component to submit for a final grading at the end of the year. The final redesign of the course changed the overwhelming material presentation to a sequence of slowly presented units of information. The course gives some choices, like technology and project or tools to use, but there are no choices on methodology and homework assignment to reduce complexity. 


\subsection{Phontasia}

Phontasia, shown in Figure 8, is an iPad game (freely available via Appstore) that has educational content $[4,5]$. It has been successfully deployed in schools and has demonstrated an increase in skill level for the academic content presented within the game. The content of the game relates to phonics for German orthography and allows children to proceed from simple patterns to more complex patterns in the same way phonics does that for English. The game is set up as a magician's lab where the player mixes potions of letters into words. The potions become increasingly complex. Observation of game use has shown that it is highly addictive in addition to improving the skills. In fact, becoming expert at the skill is the central learning goal that children are pursuing because the skill is gained and the new level of difficulty is the reward, as new positions become available ("Tage" vs. "trage").

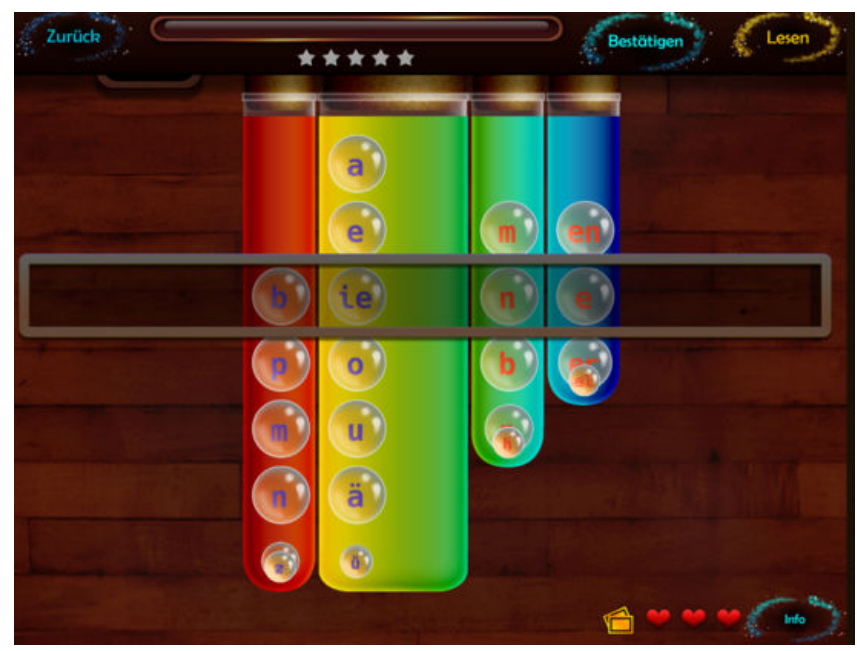

Fig. 8. Phontasia User Interface (See also [3]).

Graphics are beautiful and supported with sounds that match the underlying theme and the task. There are negative rewards, a heart can be lost three times to catapult players back to the start (similar to the game of Ludo). The reward is indirect in that correctness of the work results in the ability to reach the next level. The next level has a larger number of potions resulting in new opportunities to explore and with that new difficulties and new potions to mix in. With this power comes difficulty of words to be spelled. The students learn to spell words that they had been previously denied because the necessary potions were not yet acquired. It is easy to start and stop playing at any time. Stopping in the middle of the most successful streak is even a good idea because kids cannot wait to come back and play again to prove they can reach the next level. There 

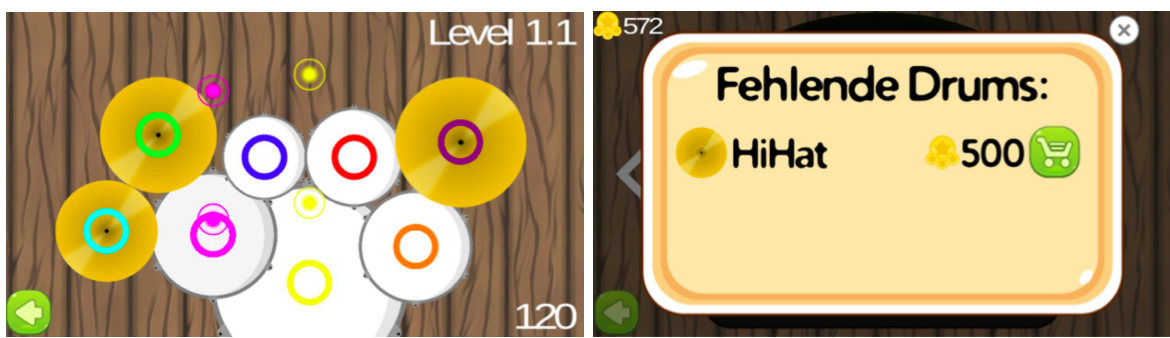

Fig. 9. Drumstix User Interface. The left shows the current drumset and sounds moving down that should be hit as they hit the center of the drum. Points gained from playing can be used in the shop to buy new drums to open new rhythms for playing/learning. (See also [3])

is intense competition with self in order to reach the next level, without losing a heart, faster than last time, improving automaticity and proficiency in the player (learner). Nothing else happens in this game except word spelling and the sounds of the magic mix.

There are 12 levels, a lot for a first or second grader. Each level adds only one small additional potion, offering new elements and challenges. They look and feel like rewards because the children can finally spell new words that they had been waiting for and were prevented from spelling previously (e.g. due to orthographic misconceptions by the player that result in learning). Each level can be played again. In fact, many children go back to replay the lower levels because they enjoy feeling comfortable with already mastered skills.

\subsection{Drum Stix}

Drum Stix is a game designed to teach rhythm. The game should have easy on-boarding and progression with constant improvement. Therefore, a complex original design idea was rejected for a simplified level design. Maximally simple and dedicated only to the content in question, the app is opened and a play button leads directly to the drums, which are the center of learning. In the first level, 2 drums are visible: 'Kick' and 'Snare'.

Each level consists of one task. A song is played in the background. Each drum is marked with a color and number. The progress-bar (for the song) indicates which drum should be played (Karaoke style). Missing a drum-beat results in a mark-down. Correct performance results in a mark-up of points. As the player repeats this rhythm, the karaoke support is removed. The level ends with the first mistake the user commits. As the levels ends, the user is shown his/her own current and his/her highest score. Played levels can be repeated any time, even as new levels open up.

Gamers can individually adjust the drums according to their needs. They can be placed differently or new drums can be purchased with the collected coins. In buying a new drum, the next level starts. Any open level can be played with 
the purchased drums. With the increasing number of drums, the game becomes more difficult. More coins can be won and bigger, additional instruments bought. Rhythms grow faster and more complex. While the first purchase is easy to obtain, further advancement is based on improved skill. There are a large number of levels and care will be taken to create fun graphics.

Figure 9 shows the design for DrumStix. It depicts drums and sounds that are falling from the top and need to be tapped in time as they hit the corresponding drums. The graphic to the right shows that the players earned points can be used to buy items that allow me to learn higher skills, in this case a new drum.

\section{Game Analysis}

In this section, we analyze existing learning environments. First, we take a look at the traditional school setting from the game point of view. Then we look at several games that have already been used in schools.

\subsection{Generic Educational System}

Analyzing the generic learning environments, that still pervade most of the education system, in terms of this anti-pattern one can see some design issues with regard to enjoying learning in schools or universities today. While schools have levels (first grade, second grade, ...), there is no individual speed. In fact, there often is competition with others and after a level is finished, no improvement is possible. A bad grade not only can not be improved, but can permanently hold students back in future levels.

While grades can be seen as rewards (for those who do well), they do not represent new tools for solving more complex problem sets. They may not even accurately reflect skills by themselves $[25,31,30]$. Students tend to have little knowledge of their own skills since there is no progress bar during the course of one class (with respect to skills - there are progress bars in terms of time and exam dates). The learning path is also very restricted with few electives and no control over the speed at which the content will be mastered.

Furthermore, the on-boarding process and further progression is not always easy, "I have no time to learn, I need to prepare for the exam next week" - is a typical anti-pattern in the game of learning.

Finally, the units of the game are often quite long, if we can measure them by time between exams. In school, there are weeks, at University there can be whole semesters between exams and level-unlocks. The number of levels with respect to the content are additionally too few. So learning, in our society has not yet matched the pattern of good game design for the general population. It remains to be proven quantitatively whether good game design in education improves the skills outcome. 


\subsection{Fingu - A Math Game}

Fingu is an iPad game that has educational content and can be downloaded for free from the AppStore $[15,1]$. It has been tested in schools, and several schools, especially in Sweden, have downloaded the game. The content of the game relates to number sense, which is foundational to the development of arithmetic competence in addition and subtraction. According to Neuman [20], mastering elementary number concepts means understanding natural numbers in the range of one to ten as part-whole relations (e.g. 6 is constituted by 5 and 1, but also by 4 and 2 and so forth).

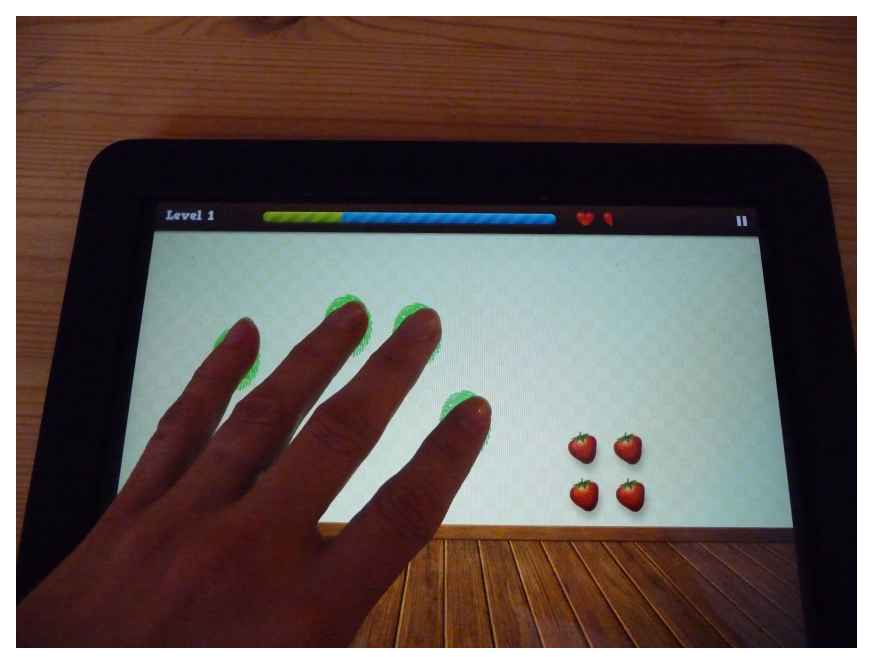

Fig. 10. Fingu User Interface

In Fingu one or two small moving sets of pieces of fruit are shown and the player has to determine how many pieces of fruit there are. Before time runs out the player has to place as many fingers on the screen as there are pieces of fruit. Figure 10 The sets are shown for a short time, but after they have disappeared the player gets some extra time to answer. Fingers can be placed anywhere on the screen. Once a finger is placed on the screen a timer is started to determine when the answer will be registered. The starting of this timer is made visible as a fingerprint. The fingerprints change color in order to indicate that a final answer has been registered. Before the answer is registered the player can (by default within part of a second) remove or add fingers and each change in finger configuration restarts the timer until a stable configuration is held down long enough.

There are 7 levels, and on each level there are a number of configurations of number patterns $(10,12$ or 15), which are shown twice in random order. If the player answers correctly the first time a configuration is shown, the exposure 
time will be shorter as the configuration is shown the second time. On the first level the maximum total number of pieces of fruit is 5 , on the second level 6 etc., to 10 pieces of fruit on level 6 and 7 . On each level some new configurations are introduced as well. One proceeds to the next level by answering correctly to the most assignments. If the player gives an incorrect answer he/she will lose a heart. If the player runs out of time only half a heart is lost. When all the hearts are lost before the 20 assignments (24 or 30 for the higher levels) have been given, the player has to start all over at the same level. Players choose their personal character on the first screen and can continue playing on the levels that they have opened up.

Graphics are designed by a professional game design company (Image and Form in Gothenburg), and are supported with sounds that match the underlying theme and the task. There are negative rewards, a heart is lost when giving an incorrect answer, and half a heart is lost when not answering within the given time. If all hearts are lost, the player has to restart the level. There is a direct reward for answering correctly in the form of three funny characters that appear, or a negative reward in the form of a crying onion. There is also an indirect reward in that correctness of the work results in the ability to reach the next level. The next level has new configurations that are harder to master, but there is no increase in playing abilities. Each level offers new configurations, both in terms of new patterns for the same number of objects, and in terms of higher numbers of objects. The students learn to immediately see number patterns and add the numbers in to patterns up to higher sums, which also requires them to coordinate their fingers more quickly. It is easy to start and stop playing at any time. However, when stopping in the middle of a level, the level has to be replayed, unless the player has only paused the game. The user can compete with him/herself to reach the next level, and to play a level without losing any of the hearts. The number of hearts left is shown when completing the level. However, the number of hearts preserved on each level is only shown on an overview screen after finishing all levels, not in-between. This makes it hard for children to know how to improve themselves on a single level. Nothing else happens in this game except recognizing number patterns and addition of number patterns which have to be expressed by a number of fingers.

There are 7 levels, which is enough for a pre-school/first grade child. Each level adds either some patterns for previously encountered numbers, or patterns for new numbers. Although there are new elements on each level that make the assignment more challenging, there are no radically new kinds of challenges to look forward to. Each level can be played again, and many children go back to replay the lower levels because they enjoy feeling comfortable with already mastered skills.

Summing up, while Fingu has the potential to be addictive, the fact that the child is unable to see how well they did on each level before finishing all levels makes it less interesting to compete with oneself. Furthermore, the kind of challenge remains the same throughout the game; there are no real new kinds of challenges to look forward to. In combination with the fact that some children 
find the coordination of their fingers for the higher sums quite difficult, many children quit playing the game before reaching the highest level.

\subsection{Teach Your Monster to Read - A Literacy Game}

Teach Your Monster to Read $\left(\mathrm{TYMTR}^{6}\right)$ is available both as a paid-for app (on iPhone, iPad, Android and Kindle) and can also be accessed for free via a website (note the version analysed was downloaded in July 2017 and there have subsequently been updates that have added additional features). It is designed to support the teaching of phonics and is specifically tailored to the government programme, Letters and Sounds, which is followed by the majority of primary schools in England. The game is predominantly aimed at young children learning to read, it is split into 3 games (focused on letters/sounds, words, and simple sentences) and is intended to cover two years of learning.

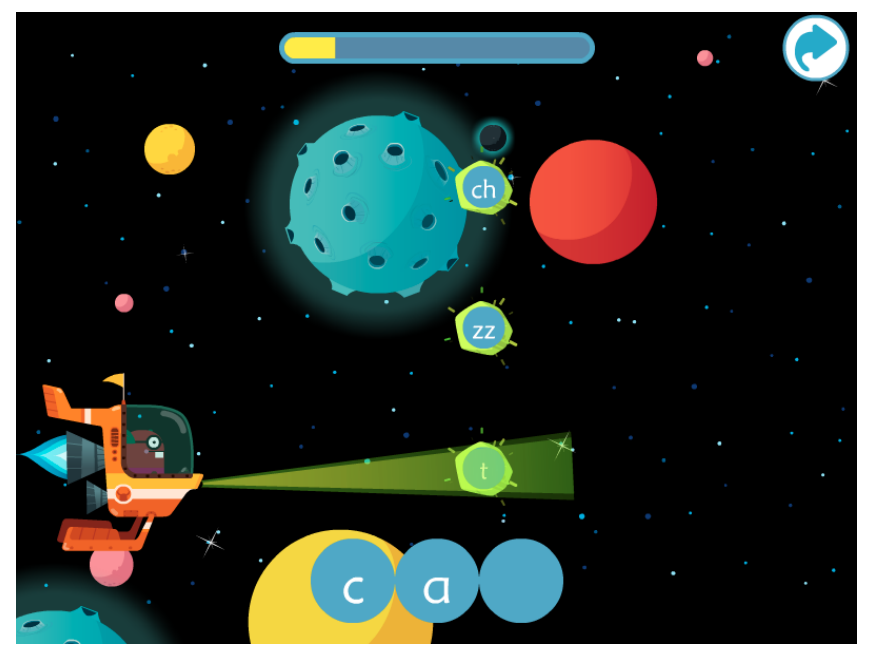

Fig. 11. Teach Your Monster to Read.

In TYMTR the child gets to customize their own monster avatar. They then navigate a world in which they are tasked with completing various reading skill focused mini-games in order to help their monster. New content is introduced via teaching videos and the mini-games provide opportunities to both learn new content as well as practice previously learning concepts and develop their speed and accuracy in reading. As the player successfully completes mini-games further content is unlocked and when they leave the game their progress is saved within their own account. The game contains 47 levels (represented as planets grouped into galaxies), is designed to fit into short play sessions so it can be easily incorporated into lessons, and contains approximately 8 hours play.

\footnotetext{
${ }^{6}$ https://www.teachyourmonstertoread.com/
} 
Graphics are beautiful and supported by sounds, music and narrated content that match the underlying theme and the task (see Figure 11). Within each minigame the player is rewarded for correct answers through positive sound effects, character animations and sometimes praise. At the end of levels the player also gets the opportunity to collect stars as well as food that you can eat (but has no direct impact on the game so the reward does not fold back to new game capabilities). The progress bar also fills up, but the link between the achievement and the amount of progress made towards the goal is not very clear through this mechanism. The player is able to spend the stars on buying things for their avatar such as different clothing for your monster, which have no impact on game play. The player is also rewarded through advancements in the game narrative and the unlocking of new content within the game. Content is grouped, so a player works on multiple concepts (of similar difficulty) at the same time, for instance the graphemes s, a, t, p. The player has to demonstrate knowledge of all of these concept before they can move on. If a player struggles with a particular concept they encounter this more frequently within the games. Over the three games the player builds on their knowledge of reading letters, word and then simple sentences (one bit builds up to the next). Alongside this, the variety of game mechanics encourages players to develop reading skills such as blending and segmenting as well as explicitly practicing semi-decodable 'tricky' words. It is easy to start and stop playing at any time, with the progress saved within the game. However, when stopping in the middle of a level, the level has to be replayed. There is no competition with oneself built into the games, as allows the player to have an unlimited number of attempts to pass a level and the number of attempts (as well as the time taken) is not used to differentiate attempts at the same level. The narrative encourages the player to move on rather than go back to earlier games and the player practices previously learned content through it being presented in differently skinned mini-games, which avoids the game feeling repetitive. There are additional game elements designed around the core content which include a rich animated narrative, avatar customization as well as minigames which involve solely collecting stars (and no learning) highlight that there are additional things happening around the core game focus.

There are 47 levels, which differentiate between learning and practice games. There are also variations across these levels in terms of the rewards gained and also different types of feedback for getting an answer incorrect. The game does not convince the player that new elements should be anticipated. They appear without any hype as the player progresses. None of the levels can be replayed. Once the player has progressed there is no way to go back, unless they reset the game completely to the starting point.

In summary, TYMTR mixes elements of consistency with new content, rewards, narrative elements and game types to maintain the child's engagement. It is easy to play for short periods and come back to the game, but the game encourages the player to continually progress forward through requiring the player to reach binary success criteria rather than encouraging them to return to earlier parts of the game to improve their accuracy. This may result in the potential of 
players becoming stuck at a certain level and not continuing with the game as they are no longer able to make progress. The additional elements external to the core game play, although engaging, may frustrate players looking to make quick progress through the games and also decreases the amount of learning time within any given play period.

\section{Summary of Games Analysis and Design}

This section compares the pattern and anti-pattern items for each of the games or school situations that were designed or analyzed in the previous sections. The goal is to see whether there are any commonalities of missing items that can then give a strong indication of how to improve these games with academic content. Table 3 shows the result for both pattern and anti-pattern items in the derived framework.

It can be seen that aspects of learning and increasing difficulty are usually covered in the games we looked at. However, it is underestimated in the studied designs how important some other aspects are. Namely, the following points should be taken more strongly into account; they combine several features of the pattern/anti-pattern analysis:

1. Rewards should directly enable the student to apply the newly won "gadget" to learning new skills. (For example, a reward is a new drum that needs to be mastered in the new level.)

2. Students like to have the option to repeat a level and improve their skills, thereby competing with themselves. This encompasses the students knowledge about their own performance at any time in the game and the power to change it!

\section{Conclusion and Future Work}

This paper describes a design recipe and an anti-pattern for the design of motivational educational games. Both resulted from a survey among a large number of participants with different demographics. Although it was shown that demographics may differ in certain aspects of game features, there are nonetheless several very important commonalities. Those commonalities are that difficulty and the ability to improve support fun, that rewards should grant new abilities for learning and that competition is mostly relevant with respect to competing with oneself. We have shown how the use of levels is constructive for users. The paper also describes the application of the recipe during the design of a new game, and how both the recipe and the anti-pattern can be used to analyze and suggest improvements for several existing games from different domains. While there are other studies providing recipes for gamification [21] or blended learning [19], these are not based on large numbers of participants, nor are they focusing on generic vs. specific motivators as a function of demographics. These 
Table 3. Comparison of Games and School for Pattern and Antipattern Elements; X stands for element is present. ( $\mathrm{SE}=$ Software Engineering)

\begin{tabular}{|c|c|c|c|c|c|c|c|}
\hline & & \begin{tabular}{|l|} 
School \\
SE
\end{tabular} & \begin{tabular}{|l|} 
School \\
classic
\end{tabular} & $\begin{array}{l}\text { Writing } \\
\text { Phont. }\end{array}$ & $\begin{array}{l}\text { Reading } \\
\text { TYMTR }\end{array}$ & \begin{tabular}{|l|} 
Rhythm \\
Drums.
\end{tabular} & $\begin{array}{l}\text { Math } \\
\text { Fingu }\end{array}$ \\
\hline $\begin{array}{l}\text { Pattern } \\
\text { Desired } \\
\text { Features }\end{array}$ & $\begin{array}{l}\text { Graphics } \\
\text { Rewards (related to skill) } \\
\text { Increased Difficulty } \\
\text { Increased Knowledge } \\
\text { Easy start/stop } \\
\text { Competition (self) } \\
\text { Nothing else } \\
\text { Many Levels } \\
\text { Frequent New Elements } \\
\text { Replay Level (infinite) }\end{array}$ & $\begin{array}{l}\mathrm{x} \\
\mathrm{x} \\
\mathrm{x} \\
\mathrm{x} \\
\mathrm{x} \\
\mathrm{x} \\
\mathrm{x} \\
\mathrm{x} \\
\mathrm{x}\end{array}$ & $\begin{array}{l}\mathrm{x} \\
\mathrm{x}\end{array}$ & $\begin{array}{l}x \\
x \\
x \\
x \\
x \\
x \\
x \\
x \\
x \\
x\end{array}$ & $\begin{array}{l}\mathrm{x} \\
\mathrm{x} \\
\mathrm{x} \\
\mathrm{x} \\
\\
\mathrm{x} \\
\mathrm{x}\end{array}$ & $\begin{array}{l}\mathrm{x} \\
\mathrm{x} \\
\mathrm{x} \\
\mathrm{x} \\
\mathrm{x} \\
\mathrm{x} \\
\mathrm{x} \\
\mathrm{x} \\
\mathrm{x} \\
\mathrm{x}\end{array}$ & $\begin{array}{l}\mathrm{x} \\
\mathrm{x} \\
\mathrm{x} \\
\mathrm{x} \\
\mathrm{x} \\
\mathrm{x} \\
\mathrm{x}\end{array}$ \\
\hline $\begin{array}{l}\text { Anti- } \\
\text { pattern } \\
\text { Undesired } \\
\text { Features }\end{array}$ & \begin{tabular}{|l|} 
Single Level \\
Bad Graphics \\
Unrelated Awards \\
Little self-awareness of skill \\
Too complex onboarding \\
Long unit of play \\
No view on own high-score \\
No replay of level \\
Too much unleveled material \\
Path without choice \\
Too much repetition \\
No individual speed \\
Competition with others
\end{tabular} & $\mathrm{x}$ & $\begin{array}{l}\mathrm{x} \\
\mathrm{x} \\
\mathrm{x} \\
\mathrm{x} \\
\mathrm{x} \\
\mathrm{x} \\
\mathrm{x} \\
\mathrm{x} \\
\mathrm{x}\end{array}$ & & $\begin{array}{l}x \\
x \\
x\end{array}$ & $\mathrm{x}$ & $\mathrm{x}$ \\
\hline
\end{tabular}

results have once more led the authors to believe that good game design principles are necessary to put the enjoyment back into learning while improving learner skills. The work described in this paper can inspire further research into how emotions are created in more detail by refining the questions in the survey. Furthermore, in order to show the relevance of game design for educational content, there must be more focus on measuring learning impact. According to the literature [9] few studies have measured both motivation and skill improvement, and many studies are performed in a specific environment without any quantitatively motivated framework and with a small number of participants. While there are some exeption (e.g. the study by Novak et al. [22]), more research effort is needed regarding generalizability and outcomes assessment. 


\section{References}

1. Barendregt, W., Lindström, B., Rietz-Leppänen, E., Holgersson, I., Ottosson, T.: Development and evaluation of fingu: A mathematics ipad game using multi-touch interaction. In: Proceedings of the 11th international conference on interaction design and children. pp. 204-207. ACM (2012)

2. Berkling, K.: Connecting peer reviews with students' motivation - onboarding, motivation and blended learning. In: Helfert, M., Restivo, M.T., Zvacek, S., Uhomoibhi, J.O. (eds.) CSEDU 2015 - Proceedings of the 7th International Conference on Computer Supported Education, Volume 2, Lisbon, Portugal, 23-25 May, 2015. pp. 24-33. SciTePress (2015)

3. Berkling, K., Faller, H., Piertzik, M.: Avoiding failure in modern game design with academic content - A recipe, an anti-pattern and applications thereof. In: Escudeiro, P., Costagliola, G., Zvacek, S., Uhomoibhi, J.O., McLaren, B.M. (eds.) CSEDU 2017 - Proceedings of the 9th International Conference on Computer Supported Education, Volume 2, Porto, Portugal, April 21-23, 2017. pp. 25-36. SciTePress (2017)

4. Berkling, K., Pflaumer, N.: Phontasia - a phonics trainer for German spelling in primary education Singapore, September 19, 2014. In: Berkling, K., Giuliani, D., Potamianos, A. (eds.) The 4st Workshop on Child, Computer and Interaction, WOCCI 2014, Singapore, September 19, 2014. pp. 33-38. ISCA (2014), \url \{http: //www.isca-speech.org/archive/wocci_2014/wc14_033.html\}

5. Berkling, K., Pflaumer, N., Lavalley, R.: German phonics game using speech synthesis - a longitudinal study about the effect on orthography skills Education, SLaTE 2015, Leipzig, Germany, September 4-5, 2015. In: Workshop on Speech and Language Technology in Education. SLaTE, vol. 6, pp. 167-172. ISCA(ISCA) International Speech Communication Association (2015), Jurl\{@http://www. isca-speech.org/archive/slate_2015/sl15_167.html\}

6. Berkling, K., Thomas, C.: Gamification of a software engineering course and a detailed analysis of the factors that lead to it's failure. In: Interactive Collaborative Learning (ICL), 2013 International Conference on. pp. 525-530. IEEE (2013)

7. Berkling, K., Zundel, A.: Change management: Overcoming the challenges of introducing self-driven learning. iJEP 5(4), 38-46 (2015), http://www . online-journals .org/index.php/i-jep/article/view/4945

8. Bianco, A.T., Higgins, E.T., Klem, A.: How fun/importance fit affects performance: relating implicit theories to instructions. Personality \& social psychology bulletin 29(9), 1091-1103 (2003)

9. Boyle, E.A., Hainey, T., Connolly, T.M., Gray, G., Earp, J., Ott, M., Lim, T., Ninaus, M., Ribeiro, C., Pereira, J.: An update to the systematic literature review of empirical evidence of the impacts and outcomes of computer games and serious games. Computers \& Education 94, 178-192 (2016)

10. Campbell, I.: Chi-squared and Fisher-Irwin tests of two-by-two tables with small sample recommendations. Statistics in medicine 26(19), 3661-3675 (2007)

11. Dicheva, D., Dichev, C., Agre, G., Angelova, G.: Gamification in Education: A Systematic Mapping Study. Journal of Educational Technology \& Society 18(3), 75-88 (2015)

12. Dickey, M.D.: K-12 teachers encounter digital games: A qualitative investigation of teachers' perceptions of the potential of digital games for K-12 education. Interactive Learning Environments 23(4), 485-495 (2013) 
13. Egenfeldt-Nielsen, S., Smith, J.H., Tosca, S.P.: Understanding video games: The essential introduction. Routledge, New York and London, third edition edn. (2016)

14. Hanus, M.D., Fox, J.: Assessing the effects of gamification in the classroom: A longitudinal study on intrinsic motivation, social comparison, satisfaction, effort, and academic performance. Computers \& Education 80, 152-161 (2015)

15. Holgersson, I., Barendregt, W., Rietz, E., Ottosson, T., Lindström, B.: Can children enhance their arithmetic competence by playing a specially designed computer game? Cursiv [publisher: Institut for Didaktik, Danmarks Pædagogiske Universitetsskole, Aarhus Universitet, DK] 18, 177-188 (2016)

16. Koivisto, J., Hamari, J.: Demographic differences in perceived benefits from gamification. Computers in Human Behavior 35, 179-188 (2014)

17. Koster, R.: A theory of fun for game design. O'Reilly Media Inc, Sebastopol, CA, second edition edn. (2014)

18. Malone, T.W., Lepper, M.R.: Making learning fun: A taxonomy of intrinsic motivations for learning. Aptitude, learning, and instruction 3(1987), 223-253 (1987)

19. Naaji, A., Mustea, A., Holotescu, C., Herman, C.: How to Mix the Ingredients for a Blended Course Recipe. BRAIN. Broad Research in Artificial Intelligence and Neuroscience 6(1-2), 106-116 (2015)

20. Neuman, D.: The origin of arithmetic skills: A phenomenographic approach (1987)

21. Nicholson, S.: A RECIPE for Meaningful Gamification. In: Reiners, T., Wood, L.C. (eds.) Gamification in Education and Business, pp. 1-20. Springer International Publishing (2015)

22. Novak, E., Johnson, T.E., Tenenbaum, G., Shute, V.J.: Effects of an instructional gaming characteristic on learning effectiveness, efficiency, and engagement: Using a storyline for teaching basic statistical skills. Interactive Learning Environments 24(3), 523-538 (2016)

23. Ryan, Deci: Intrinsic and Extrinsic Motivations: Classic Definitions and New Directions. Contemporary educational psychology 25(1), 54-67 (2000)

24. Salen, K.: Quest to learn: Developing the school for digital kids. The John D. and Catherine T. MacArthur Foundation reports on digital media and learning, MIT Press, Cambridge, Mass. (2011)

25. Schuler, H., Funke, U., Baron-Boldt, J.: Predictive Validity of School Grades -A Meta-analysis. Applied Psychology 39(1), 89-103 (1990)

26. de Sousa Borges, S., Durelli, V.H.S., Reis, H.M., Isotani, S.: A systematic mapping on gamification applied to education. In: Cho, Y., Shin, S.Y., Kim, S., Hung, C.C., Hong, J. (eds.) the 29th Annual ACM Symposium on Applied Computing. pp. 216-222 (2014)

27. Squire, K.: From Content to Context: Videogames as Designed Experience. Educational Researcher 35(8), 19-29 (2006)

28. Stott, A., Neustaedter, C.: Analysis of gamification in education. Surrey, BC, Canada 8 (2013)

29. Suarez Caraballo, L.M.: Using Online Mathematics Skills Games To Promote Automaticity. Ph.D. thesis, Cleveland State University (01012014)

30. Trapmann, S., Hell, B., Hirn, J.O.W., Schuler, H.: Meta-Analysis of the Relationship Between the Big Five and Academic Success at University. Zeitschrift für Psychologie / Journal of Psychology 215(2), 132-151 (2007)

31. Trapmann, S., Hell, B., Weigand, S., Schuler, H.: Die Validität von Schulnoten zur Vorhersage des Studienerfolgs - eine Metaanalyse 1Dieser Beitrag entstand im Kontext des Projekts "Eignungsdiagnostische Auswahl von Studierenden", das im Rahmen des Aktionsprogramms "StudierendenAuswahl" des Stifterverbands für die 
Deutsche Wissenschaft und der Landesstiftung Baden-Württemberg durchgeführt wird. Zeitschrift für Pädagogische Psychologie 21(1), 11-27 (2007)

32. Vallerand, R.J., Gauvin, L.I., Halliwell, W.R.: Negative Effects of Competition on Children's Intrinsic Motivation. The Journal of Social Psychology 126(5), 649-656 (1986)

33. Vaz de Carvalho, C., Escudeiro, P., Coelho, A. (eds.): Serious Games, Interaction, and Simulation. Lecture Notes of the Institute for Computer Sciences, Social Informatics and Telecommunications Engineering, Springer International Publishing, Cham (2016)

34. Wiggins, B.E.: An Overview and Study on the Use of Games, Simulations, and Gamification in Higher Education. International Journal of Game-Based Learning 6(1), 18-29 (2016) 